\title{
Serology for Helicobacter pylori compared with symptom questionnaires in screening before direct access endoscopy
}

\author{
M A Mendall, R P Jazrawi, J M Marrero, N Molineaux, J Levi, J D Maxwell, T C Northfield
}

\begin{abstract}
This prospective study aimed to compare serology for Helicobacter pylori with two, symptom questionnaires in screening patients before direct access endoscopy. Methods were compared in terms of the number of endoscopies saved and pathology missed in $\mathbf{3 1 5}$ patients referred to a gastroenterology unit by 65 local GPs. The serology used was based on an acid glycine extract of $H$ pylori. One in-house questionnaire was based on the Glasgow dyspepsia (GLADYS) system and the other questionnaire was that reported by Holdstock et al. A cut off point of $6 \cdot 3$ $\mathrm{U} / \mathrm{ml}$ for $H$ pylori serology was selected for screening patients (97\% sensitive and $75 \%$ specific). Serology was combined with a history of NSAID usage in determining who should have endoscopy. For the inhouse questionnaire, a cut off score of more than 8 out of a possible maximum of 18
\end{abstract} was chosen, after prior evaluation in 118 patients referred for direct access endoscopy (the sensitivity for detection of peptic ulcer was $88 \%$, specificity $61 \%$ ). A cut off score of more than $\mathbf{4 1 2}$ was used for the Holdstock questionnaire. In patients under 45 years, serology detected more peptic ulcers than the in-house questionnaire and the Holdstock questionnaire $(27 / 28 v 24 / 28$, NS and $v 20 / 28, p<0.05$ respectively). The Holdstock questionnaire saved significantly more endoscopies than the other two methods (76/149 $v 57 / 149$ for the in-house questionnaire, $p=0.05$ and $59 / 149$ for serology, $p=0.05$ ). In all age groups combined, serology was significantly better than the in-house and Holdstock questionnaires at detecting peptic ulcers and gastric cancer $(61 / 63,52 / 63$, $p<0.02$, and 50/63, $<<0.01$ respectively). But serology saved significantly fewer endoscopies (89/315, 135/315, $p<0 \cdot 005$, and $119 / 315, p<0.05$ respectively). Serology was inferior to the Holdstock questionnaire at detecting severe oesophagitis. It is concluded that serology is the method of choice in screening before direct access upper gastrointestinal endoscopy in those under 45 years. It best combines a high sensitivity for peptic ulcer disease with a large reduction in unnecessary negative endoscopies. (Gut 1995; 36: 330-333)

Keywords: Helicobacter pylori, serology, symptom questionnaire, direct access endoscopy.
Endoscopy is the investigation of choice in dyspepsia. Direct access endoscopy can reduce the time between presentation and diagnosis. It saves on unnecessary outpatient consultations, and can reduce inappropriate prescribing, ${ }^{1}$ but results in an increased workload. ${ }^{2}$ Thus, some method of screening out subjects who are at low risk of clinically important pathology is desirable.

Helicobacter pylori is an important factor in the pathogenesis of peptic ulcer. Ninety five per cent of duodenal ulcers and $67-87 \%$ of gastric ulcers are associated with this infection, ${ }^{3}$ while many of the $H$ pylori negative ulcers are associated with the use of non-steroidal anti-inflammatory drugs (NSAIDs). ${ }^{4}$ We and others have assessed a strategy of not endoscoping those $H$ pylori seronegative subjects aged less than 45 who are not taking NSAIDs and have shown it to have a sensitivity of $96-97 \%$ for detecting pathology while enabling the avoidance of $23-30 \%$ of endoscopies when performed in all age groups. 56

Attempts have been made to derive scoring systems, based on symptoms, which predict the presence or absence of pathology on endoscopy, the advantage of this approach being cost. Varying results have been reported, with sensitivities for the detection of major pathology from 86-96\% and savings in endoscopic workload varying from $23-33 \% .{ }^{78}$

We compared prospectively a screening strategy of not endoscoping $H$ pylori seronegative subjects who were not taking NSAIDs with two symptom questionnaires in a direct access endoscopy clinic population. One of the symptom questionnaires was that of Holdstock which gives the best results of any so far reported, and the other was one developed inhouse from the Glasgow computerised dyspepsia questionnaire by Crean. ${ }^{9}$

\section{Methods}

PRIOR VALIDATION OF SEROLOGY

The serology was validated on 295 consecutive subjects (mean age 51, range 15-93) referred from a gastrointerology clinic for endoscopy. Upper gastrointestinal endoscopy was performed after an overnight fast. Three biopsy specimens were taken from the antrum within $3 \mathrm{~cm}$ of the pylorus. Two biopsy specimens were submitted for histology for the identification of $H$ pylori after staining with haematoxylin and eosin and one was used to perform a biopsy urease test (CLO test), positive in 24 
hours. Patients were considered infected if either of the tests was positive.

\section{PRIOR VALIDATION OF SYMPTOM}

QUESTIONNAIRES

The in-house questionnaire consisted of 14 questions which covered the following: epigastric pain, its relief by food, its duration, vomiting, smoking, alcohol intake, previous ulcer, history of ulcer treatment and family history. The answers were given weights of 0 , 1 , or 2 . The questions and score were based on criteria developed in Glasgow as part of the development of the GLADYS diagnostic computer system. ${ }^{9}$ It was validated on 118 patients (mean age 36, range 22-75) referred for direct access endoscopy.

The Holdstock questionnaire ${ }^{7}$ comprised 6 questions with different weights. These questions concerned age, sex, smoking, history of peptic ulcer, family history of peptic ulcer, and hiatus hernia. A cut off score of more than 412 gave a sensitivity for the detection of serious pathology of $97 \%$ with potential savings of $26 \%$ of all endoscopies in the assessment previously reported. ${ }^{7}$

\section{STUDY DESIGN}

The GPs who referred patients for direct access endoscopies were given guidelines for referral according to the British Society of Gastroenterology's recommendations. GPs were advised that subjects with sinister symptoms (that is, anaemia, weight loss, dysphagia) were not suitable for direct access endoscopy. They were asked to stop their patients taking $\mathrm{H}_{2}$ antagonists two weeks before endoscopy and appointments were booked for two weeks later if at the time of the request the subject was taking these drugs.

Information on NSAID use was collected from the direct access patients and from 205 of the clinic patients. A history of regular NSAID use was deemed to be present when the use of NSAIDs in anything other than low dosage preceded the onset of symptoms.

Approval was obtained from the local hospital ethical committee.

The two questionnaires and the serology were tested prospectively on 315 consecutive subjects (median age 48, range 15-86, 54\% male) directly referred by their GP for investigation of dyspepsia. Questionnaires were administered by a research nurse before the endoscopy, and the endoscopist was unaware

TABLE I Prospective comparison of serology and questionnaire screening for dyspepsia in the under 45 year olds with respect to findings on esophagoduodenogastroscopy

\begin{tabular}{lllll}
\hline & $\begin{array}{l}\text { Normal, } n=120 \\
\text { (\% in whom } \\
\text { endoscopy } \\
\text { not required) }\end{array}$ & $\begin{array}{l}\text { Duodenal ulcer, } \\
n=26 \\
\text { (\% detected) }\end{array}$ & $\begin{array}{l}\text { Gastric ulcer, } \\
n=2 \\
\text { (\% detected) }\end{array}$ & $\begin{array}{l}\text { Moderate/severe } \\
\text { oesophagitis } \\
n=1 \text { (\% detected) }\end{array}$ \\
Test & 48 & 96 & 100 & 100 \\
\hline $\begin{array}{l}\text { Serology+NSAID use } \\
\text { In-house questionnaire }\end{array} \quad$ & 44 & 88 & 50 & 100 \\
$\begin{array}{l}\text { (score 8+) } \\
\text { Holdstock questionnaire }\end{array}$ & 57 & 73 & 50 & 100 \\
$\begin{array}{c}\text { Hcore 412+) } \\
\quad(\text { score 368+) }\end{array}$ & 45 & 73 & 100 & 100 \\
\hline
\end{tabular}

of the results. All subjects were endoscoped irrespective of their serological or questionnaire findings in order to assess the pathology that would have been missed in those screened out of endoscopy by the different procedures.

Serological testing for $H$ pylori infection was performed using an ELISA based on an acid glycine extract (Helico-G, Porton, Cambridge). The test was performed in duplicate according to the manufacturer's instructions.

Statistical analysis of savings in endoscopies and pathology detected was by the $\chi^{2}$ test, using continuity corrections where appropriate.

\section{Results}

VALIDATION OF THE SEROLOGY AND THE QUESTIONNAIRES

For serology, intra-assay variation was $6 \%$ and interassay variation $10 \%$, as previously reported. Of 295 subjects referred from the clinic for upper gastrointestinal endoscopy, $62 \%$ were positive for $H$ pylori on biopsy based tests. A cut off point of $6.3 \mathrm{U} / \mathrm{ml}$ was selected for the purpose of screening the direct access patients. This optimised sensitivity at $98 \%$ and specificity at $75 \%$, as previously reported. The strategy tested prospectively was to endoscope only seropositive subjects using this cut off point, as long as they were not taking regular NSAIDs. This was defined as subjects taking NSAIDs most days for a period of at least one week, or subjects whose recent symptoms postdated the ingestion of these drugs, except cardioprotective doses of aspirin. If subjects did not fulfil these criteria, their endoscopies were said to be 'saved'.

For the in-house questionnaire, a cut off score of more than 8 out of a possible maximum of 18 was chosen (sensitivity for detection of peptic ulcer $88 \%$, specificity $61 \%$ ). Subjects with scores of less than this were considered to have had their endoscopies 'saved'.

Only 12 subjects had a positive history of NSAID use. Three of these were under the age of 45; one was seropositive and had a gastric ulcer, one was seropositive and had a normal endoscopy, and the third was seronegative. In the over 45 years age group, there was one seronegative, but NSAID positive ulcer; six NSAID positive, $H$ pylori positive subjects with a normal endoscopy; and two NSAID positive subjects who were seronegative.

PROSPECTIVE COMPARISON OF SEROLOGY AND QUESTIONNAIRE SCREENING IN THE UNDER 45 YEAR OLDS

The pathology detected in the under $45 \mathrm{~s}$ and all age groups combined is shown in Tables I and II. Serology detected all pathology except one duodenal ulcer. The in-house questionnaire missed four duodenal ulcers and one gastric ulcer, whereas the Holdstock questionnaire missed six duodenal ulcers and one gastric ulcer. Proportions of normal endoscopies which would have been saved were similar. In all age groups combined, serology and the Holdstock questionnaire detected both gastric cancers, unlike the in-house questionnaire. 
TABLE II Prospective comparison of serology and questionnaire screening for dyspepsia in all age groups with respect to findings on oesophagoduodenoscopy

\begin{tabular}{|c|c|c|c|c|c|}
\hline Test & $\begin{array}{l}\text { Normal, } n=236 \\
\text { (\% in whom } \\
\text { endoscopy not } \\
\text { required }\end{array}$ & $\begin{array}{l}\text { Duodenal ulcer, } \\
n=52 \\
\text { (\% detected) }\end{array}$ & $\begin{array}{l}\text { Gastric ulcer } \\
n=9 \\
\text { (\% detected) }\end{array}$ & $\begin{array}{l}\text { Gastric } C a, \\
n=2 \\
\text { (\% detected) }\end{array}$ & $\begin{array}{l}\text { Moderate/severe } \\
\text { oesophagitis, } \\
n=16 \\
\text { (\% detected) }\end{array}$ \\
\hline $\begin{array}{l}\text { Serology+NSAID use } \\
\text { In-house questionnaire (score } 8+\text { ) } \\
\text { Holdstock questionnaire (score } 412+\text { ) } \\
\text { Holdstock questionnaire (score } 368+\text { ) }\end{array}$ & $\begin{array}{l}35 \\
51 \\
45 \\
31\end{array}$ & $\begin{array}{l}98 \\
88 \\
79 \\
85\end{array}$ & $\begin{array}{l}89 \\
67 \\
78 \\
89\end{array}$ & $\begin{array}{r}100 \\
0 \\
100 \\
100\end{array}$ & $\begin{array}{r}69 \\
75 \\
100 \\
100\end{array}$ \\
\hline
\end{tabular}

Table III shows the number and the proportion of endoscopies saved in the under $45 \mathrm{~s}$ and all age groups combined. It excludes moderate to severe oesophagitis (there was only one case in the under $45 \mathrm{~s}$ ). In the under $45 \mathrm{~s}$, serology detected more pathology than both questionnaires, but this difference was significant only when compared with the Holdstock questionnaire.

Because the Holdstock questionnaire performed less well than reported, the optimal cut off point of a score of 368 was selected because it maximised sensitivity and specificity for pathology. It also gave a similar specificity to that in the initial report. Using the revised cut off for the Holdstock questionnaire the difference from serology in detecting peptic ulcer disease became of borderline significance in the under $45 \mathrm{~s}$ while remaining significant in all age groups. The number of endoscopies saved became similar to serology in both the under 45 s and all ages combined.

If only two peptic ulcers were to be missed by the Holdstock questionnaire in the under 45s (that is the same as with serology) the cut off point would have to be lowered to 350 and then only 16 endoscopies would have been saved, significantly fewer than serology. The effect of lowering the cut off of the in-house questionnaire in the under $45 \mathrm{~s}$ was also examined. Lowering the cut off to 6 would have missed three peptic ulcers, but would have saved only 31 endoscopies, significantly fewer than serology, while lowering the cut off point to 5 would have missed one gastric ulcer and saved just 30 endoscopies.

If the in-house questionnaire were performed first, and only those subjects with a score of more than 5 had serology performed, then $75 / 149(50 \%)$ of endoscopies would have been saved and only one gastric ulcer missed. Thirty fewer serological tests would have been performed.

\section{Discussion}

In all age groups taken together, serology for $H$ pylori was better than the two questionnaires

TABLE III Comparison of the different screening methods with regard to the proportion of endoscopies saved and pathology detected

\begin{tabular}{lllll}
\hline Test & $\begin{array}{l}\text { Endoscopies } \\
\text { saved }\end{array}$ & $\begin{array}{l}\text { Pathology } \\
\text { detected } \\
<45 s(\%)\end{array}$ & $\begin{array}{l}\text { Endoscopies } \\
\text { saved } \\
\text { all ages (\%) }\end{array}$ & $\begin{array}{l}\text { Pathology } \\
\text { detected } \\
\text { all ages (\%) }\end{array}$ \\
\hline Serology & $59 / 149(40)$ & $27 / 28(96)$ & $89 / 315(28)$ & $61 / 63(97)$ \\
In-house questionnaire & $57 / 149(38)$ & $24 / 28(86)$ & $135 / 315(43)^{\star}$ & $52 / 63(83) \dagger$ \\
Holdstock questionnaire & $76.149(51)^{\star}$ & $20 / 28(71) \dagger$ & $119 / 315(38)^{\star}$ & $50 / 63(79) \dagger$ \\
Holdstock questionnaire (cop 368) & $61 / 149(41)$ & $21 / 28(75) \ddagger$ & $81 / 315(26)$ & $55 / 79(87) \dagger$
\end{tabular}

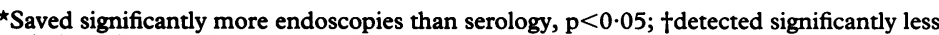
pathology than serology $p<0.05 ; \ddagger$ detected less pathology than serology $p=0.06$. in detecting peptic ulcer disease and gastric cancer in an unselected direct access endoscopy population. This was at the cost of saving fewer endoscopies. Worryingly, the inhouse questionnaire would have missed both gastric cancers in the older age group.

In the under 45 age group, where the risk of gastric cancer is low, serology again detected a higher proportion of peptic ulcers, although this difference failed to reach significance. The differences in the number of endoscopies saves were less and non-significant, except for the Holdstock questionnaire which used the higher cut off point. The effect of lowering the cut off points of the two questionnaires was also examined, and it was found that to detect the same proportion of pathology as serology, significantly fewer endoscopies would have been saved than with serology.

Any investigation should only be used if it is going to alter management. In this respect serology for $H$ pylori is a more rational investigation than a questionnaire. Apart from detecting peptic ulcer disease, which can be treated effectively by either $H$ pylori eradication therapy or by stopping NSAIDs, the management of other conditions is not altered by endoscopic diagnosis. The management of oesophagitis is symptomatic except when the disorder is complicated by stricture formation, at which time the warning symptoms of subjects not suitable for screening will be present. Furthermore, moderate to severe oesophagitis is rare in the under 45s. Both gastric cancers were detected by serology as were all the gastric cancers in two previous studies which have employed the same test, raising the possibility that it could be applied in older age groups as well. However, the smaller proportion of endoscopies which could be saved in these subjects makes screening less attractive.

In our hands, the Holdstock questionnaire did not perform as well for screening as indicated by the author's report. The reason for this is unclear. It could be due to differences in referral patterns or in the populations being screened. The Holdstock questionnaire is heavily weighted towards endoscoping older subjects, unlike the serology test and the in-house questionnaire. Our population, which comes from an inner city area of high deprivation with a large number of ethnic minorities and a high prevalence of $H$ pylori, had considerable peptic ulcer disease at a young age, whereas the Holdstock questionnaire was originally validated in an area of higher social class. It may be argued that serology and the in-house questionnaire yield different results when applied to different populations. However, one can extrapolate from the results 
of the present study, that if serology were to be applied as a screening procedure in a low $H$ pylori prevalence population, a larger proportion of endoscopies would be saved.

Serology is more expensive than a questionnaire, but the reduced chance of missing peptic ulcer disease is adequate compensation. Furthermore, serology is considerably less expensive than endoscopy. The serology test described here costs approximately $£ 10$ per patient tested including technician time, which compares favourably with the cost of an endoscopy (about $£ 150$ ). If screening were targeted at the under $45 \mathrm{~s}$ only, the cost would be about $£ 20$ per endoscopy saved.

In conclusion, questionnaires 'save' more negative endoscopies, but at the expense of missing pathology. If greater importance is given to not missing pathology, serology for $H$ pylori infection is the screening method of choice before endoscopy, particularly in the under $45 \mathrm{~s}$. Whether it can be usefully combined with a simple questionnaire needs prospective evaluation.
We would like to acknowledge the provision of Helico $\mathrm{G}$ kits by Porton Cambridge, and the help given by the staff of the Norman Tanner Gastroenterology Unit.

1 Gear MWL, Wilkinson SP. Open-access upper alimentary endoscopy. Br f Hosp Med 1989; 41: 438-44.

2 Holdstock G, Wiseman M, Loehry CA. Open-access endoscopy service for general practitioners. BMF 1979; 1 : 457-9.

3 Wyatt JI. Campylobacter pylori, duodenitis duodenal ulceration. In: Rathbone BJ, Heatley RV, eds. Campylobacter pylori and gastroduodenal disease. Oxford: Blackwell Scientific Publications, 1989: 117-24.

4 Graham DY, Smith JL. Gastroduodenal complications of chronic NSAID therapy. Am 7 Gastroenterol 1988; 83: 1081-4.

5 Mendall MA, Goggin PM, Marrero JM, Levy J, Molineaux $\mathrm{N}$, Bhadue $\mathrm{S}$, et al. Helicobacter pylori screening prior to endoscopy. European fournal of Gastroenterology and endoscopy. European fourna

6 Sobala GM, Crabtree JE, Pentith JA, Rathbone BJ, Shallcross TM, Wyatt JI, et al. Screening dyspepsia by serology to Helicobacter pylori. Lancet 1991; 338: 94-6.

7 Holdstock G, Harman M, Machin D, Patel C. Prospective testing of a scoring system designed to improve case selection for upper gastrointestinal investigation Gastroenterology 1986; 90: 1164-9.

8 Davenport PM, Morgan AG, Darnborough A. Can preliminary screening of dyspeptic patients allow more effective use of investigational techniques? $B M \mathcal{F} 1985 ; 290$ : 217-9.

9 Spiegelhalter DJ, Crean GP, Holden R, Krull-Jones RP Taking a calculated risk: predictive scoring systems in dyspepsia. In: Brookstead F, ed. Peptic ulcer disease. London: pepsia. In: Brookstead F,
Churchill, 1985: 152-60. 